(C) 2019, The Authors. Published by FASS Inc. and Elsevier Inc. on behalf of the American Dairy Science Association ${ }^{\circledR}$. This is an open access article under the CC BY-NC-ND license (http://creativecommons.org/licenses/by-nc-nd/4.0/).

\title{
Integrative plasma proteomic and microRNA analysis of Jersey cattle in response to high-altitude hypoxia
}

\author{
Zhiwei Kong, ${ }^{1,2}$ Chuanshe Zhou, ${ }^{1,3 *}$ Bin Li, ${ }^{4 *}$ Jinzhen Jiao, ${ }^{1,3}$ Liang Chen, ${ }^{1,5}$ Ao Ren, ${ }^{1,5}$ Hongdong Jie, ${ }^{1}$ \\ and Zhiliang Tan ${ }^{1,3}$ \\ ${ }^{1}$ CAS Key Laboratory for Agro-Ecological Processes in Subtropical Region, National Engineering Laboratory for Pollution Control \\ and Waste Utilization in Livestock and Poultry Production, South-Central Experimental Station of Animal Nutrition and Feed Science \\ in Ministry of Agriculture, Hunan Provincial Engineering Research Center for Healthy Livestock and Poultry Production, \\ Institute of Subtropical Agriculture, The Chinese Academy of Sciences, Changsha, Hunan 410125, China \\ ${ }^{2}$ University of the Chinese Academy of Sciences, Beijing 100049, China \\ ${ }^{3}$ Hunan Co-Innovation Center of Safety Animal Production (CICSAP), Changsha, Hunan 410128, China \\ ${ }^{4}$ Institute of Animal Husbandry and Veterinary, Tibet Autonomous Regional Academy of Agricultural Sciences, \\ State Key Laboratory of Hulless Barley and Yak Germplasm Resources and Genetic Improvement, Lhasa, Tibet 850000, China \\ ${ }^{5}$ College of Animal Science and Technology, Hunan Agricultural University, Changsha, Hunan 410128, China
}

\section{ABSTRACT}

Blood has been widely collected and analyzed for diagnosing and monitoring diseases in humans and animals; a range of plasma proteins and peptide can be used as biomarkers to describe pathological or physiological status. Changes in the environment such as high-altitude hypoxia $(\mathrm{HAH})$ can lead to adaptive changes in the blood system of mammals. However, the adaptation mechanism induced by HAH remains unclear. In this study, we used 12 multiparous Jersey cattle (400 \pm 35 $\mathrm{kg}$, average $3 \mathrm{yr}$ old, dry period). We applied an iTRAQ (isobaric tags for relative and absolute quantitation) proteomics approach and microRNA (miRNA) microarray to explore differences in the plasma proteomic and miRNA profiles of Jersey cattle exposed to $\mathrm{HAH}$ conditions in Nyingchi, Tibet (altitude 3,000 m) and HAH-free conditions in Shenyang, China (altitude 50 $\mathrm{m})$. Such quantitative proteomic strategies are suitable for accurate and comprehensive prediction of miRNA targets. In total, 264 differentially expressed proteins (127 upregulated, fold-change $>1.2 ; 137$ downregulated, fold-change $<0.8)$ and 47 differential miRNAs $(25$ upregulated, fold-change $>2 ; 22$ downregulated, foldchange $<0.5)$ were observed in the HAH-stressed group compared with the HAH-free group. Integrative analysis of proteomic and miRNA profiles demonstrated that the biological processes associated with differentially expressed proteins were immune response, complement system, and conjugation system. Integrative analysis of canonical pathways showed that most were associated

Received August 8, 2018.

Accepted January 2, 2019.

*Corresponding authors: zcs@isa.ac.cn and xukesuolibin@163.com with acute phase response signaling $(\mathrm{z}$-score $=-0.125)$, liver X receptor/retinoid X receptor (LXR/RXR) activation pathway $(\mathrm{z}$-score $=1.134)$, coagulation system (z-score $=-0.943)$, and complement system (z-score $=-0.632)$. The current results indicated that Jersey cattle exposed to $\mathrm{HAH}$ could adapt to that condition through regulation of inflammatory homeostasis by inhibiting the acute phase response, coagulation system, and complement system and promoting LXR/RXR activation.

Key words: plasma proteomics, microRNA analysis, Jersey cattle, high-altitude hypoxia

\section{INTRODUCTION}

High-altitude (defined as $>2,500 \mathrm{~m}$ above mean sea level) hypoxia (HAH) readily results in a pathological state compared with the normal state in mammals, affecting the entire body, including lung (Hotta et al., 2004), brain (Kapoor, 2013), mesentery (Kotwal et al., 2015), peripheral vessels (Kotwal et al., 2007), and retina (Bhende et al., 2013). Usually, HAH affects the function of the immune system, decreasing the release of cytokines and increasing the vulnerability of the human body to infection and disease (Mishra and Ganju, 2010). Similarly, a significant effect of HAH for cows that are not native to $\mathrm{HAH}$ is the elevation of pulmonary arterial pressure (Yuan and Xie, 2005), particularly for those rapidly transported from plain to plateau. Additionally, the rate of sperm malformation increases significantly after animals suffer hypothermia and freezing injury ( $\mathrm{Hu}$ and $\mathrm{Hu}, 2015)$. The levels of serum $\mathrm{K}^{+}, \mathrm{Na}^{+}, \mathrm{Ca}^{2+}$, and $\mathrm{Cl}^{-}$of cows transferred from a low-altitude area to a high-altitude area are significantly lower than those of local cows (Zhang et al., 2012). 
As an important lactating breed in animal husbandry, Jersey cattle are primarily known for their high contents in milk of lactose (Zhang et al., 2008), protein, and fat (Wang et al., 2011). In terms of reproductive performance, the advantages of the breed mainly include early sexual maturity, no dystocia, and high fertility rate (Wang et al., 2011). Additionally, Jersey cattle have high tolerance to intake of coarse feed and high disease resistance, adaptability, feed utilization rate, and economic efficiency (Wang et al., 2018). Practices in the Tibet area of China have proven that, after crossbreeding between Jersey cattle and Tibet native cattle, performance of hybrid progeny improves significantly, primarily manifested as larger birth weight, rapid growth and development, and high milk production, among other indicators (Ma et al., 2016). Hence, there is great interest in the adaptation of Jersey cattle to high-altitude regions.

The decline in altitude-dependent atmospheric pressure and subsequent environmental pressure leads to hypoxemia and tissue hypoxia. Under exposure to hypoxia, the hypoxia-inducible transcription factors (HIF) can be activated quickly to contribute to the cell response to hypoxia (Thiersch et al., 2017). To date, numerous studies have examined adaptation mechanisms to high-altitude hypoxia in humans (Huerta-Sánchez et al., 2014), pigs (Li et al., 2013a), dogs (Gou et al., 2014), and horses (Hendrickson, 2013). Limited information is available on adaptation to a high-altitude region for Jersey cattle introduced to the Tibet Plateau.

With the rapid progress in biotechnology, proteomic and microRNA (miRNA) analyses can be applied to explore adaptation mechanisms of Jersey cattle to HAH. MicroRNAs regulate various cellular and biological processes by degradation and translational repression of mRNA (Baek et al., 2008). Previous studies reported that integrative analysis of miRNA and mRNA expression data helped to identify high confidence targets and clarify the pathogenesis of disease through bioinformatics tools (Dymacek et al., 2015). Although the expression of target genes can be regulated by miRNAs without mRNA degradation in some situations (Ma et al., 2007), miRNAs can independently repress the production of proteins (Selbach et al., 2008). Moreover, quantitative proteomic strategies are accepted as more suitable for accurate and comprehensive prediction of miRNA targets (Huang et al., 2013). In fact, quantitative proteomic strategies play a vital role in exploring the molecular pathogenesis of miRNA-regulated diseases (Ou et al., 2014). However, because of its low sensitivity, quantitative proteomic analysis is only capable of recognizing a fraction of proteins (Fukunaga et al., 2015). To compensate for this deficiency of proteomics, we selected liquid chromatography with tandem mass spectrometry (LC-MS/MS) coupled with the isobaric tags for relative and absolute quantitation (iTRAQ) technology in this study to further ensure the accuracy and precision of the results (Hanada et al., 2013).

Jersey cattle adaptations to high altitude can be better understood by comparing the variations in plasma proteomic and microRNA profiles of Jersey cattle originating from low- and high-altitude regions.

\section{MATERIALS AND METHODS}

This experiment was conducted according to the Animal Care and Use Guidelines of the Animal Care Committee, Institute of Subtropical Agriculture, The Chinese Academy of Sciences, Changsha, China (protocol ISA-201704).

\section{Animals and Experimental Design}

Twelve multiparous Jersey cattle $(400 \pm 35 \mathrm{~kg})$ were selected and randomly divided into 2 groups (6 cattle in each group) in Shenyang (altitude $50 \mathrm{~m}$; HAH-free group). One group was selected and fed in Nyingchi, Tibet (altitude 3,000 m; HAH group) for $30 \mathrm{~d}$ in the autumn. The other group was fed in Shenyang (HAHfree group) for $30 \mathrm{~d}$ in autumn.

The basal diet (Table 1) was formulated to meet the nutrient requirements for energy, protein, minerals, and vitamins according to the Feeding Standards of Dairy Cattle in China (Ministry of Agriculture, 2004). All dairy cows were fed the same TMR diets ad libitum.

Table 1. Ingredient and nutrient composition of the diet (\% of DM)

\begin{tabular}{|c|c|}
\hline Item & Content $(\%)$ \\
\hline \multicolumn{2}{|l|}{ Diet composition } \\
\hline Chinese leymus & 37.5 \\
\hline Corn silage & 22.5 \\
\hline Corn & 15.2 \\
\hline Wheat bran & 5.3 \\
\hline Soybean meal & 9.2 \\
\hline Distillers dried grains with solubles & 8.4 \\
\hline Calcium hydrophosphate & 1.4 \\
\hline Premix $^{1}$ & 0.5 \\
\hline \multicolumn{2}{|l|}{ Nutrient composition } \\
\hline $\mathrm{CP}$ & 13.1 \\
\hline NDF & 39.6 \\
\hline $\mathrm{Ca}$ & 0.6 \\
\hline $\mathrm{P}$ & 0.4 \\
\hline $\mathrm{NE}_{\mathrm{L}},{ }^{2} \mathrm{MJ} / \mathrm{kg}$ of $\mathrm{DM}$ & 5.4 \\
\hline
\end{tabular}

${ }^{1}$ One kilogram of premix contained mixed vitamins, 800,000 IU; Fe, 1,500 mg; Cu, 1,000 mg; Zn, 11,000 mg; Mn, 3,500 mg; Se, 80 mg; I, $200 \mathrm{mg}$; Co, $50 \mathrm{mg}$.

${ }^{2} \mathrm{NE}_{\mathrm{L}}$ was calculated according to Lu and Feng (2007). 


\section{Sample Preparation}

Blood samples were collected into evacuated $\mathrm{K}_{2^{-}}$ EDTA (anticoagulation) tubes through coccygeal venipuncture of all experimental animals before morning feeding on the last day of the experiment. Plasma was obtained from each blood sample by centrifugation $\left(3,000 \times g\right.$ for $10 \mathrm{~min}$ at $\left.4^{\circ} \mathrm{C}\right)$ and stored at $-80^{\circ} \mathrm{C}$ until analyzed for proteomic and miRNA analysis. Additional blood samples were collected in serum tubes on the last day of the experiment and centrifuged at 3,000 $\times g$ for $10 \mathrm{~min}$ at $4^{\circ} \mathrm{C}$. The serum samples were then stored at $-40^{\circ} \mathrm{C}$ until analysis of the immune index.

\section{Analysis of the Blood Immune Index}

The levels of IgA, IgM, and IgG were determined using cow IgA (catalog no. E10-121), IgM (catalog no. E10-101), and IgG (catalog no. E11-118) ELISA kits (Bethyl Laboratories, Montgomery, TX), respectively. Levels of IL-2 and IL-6 were determined using cow ELISA kits (Invitrogen, Carlsbad, CA). The level of tumor necrosis factor- $\alpha$ (TNF- $\alpha$ ) was measured using a cow RIA kit (North Institute of Biotechnology, Beijing, China) according to the manufacturer's instructions.

\section{Preparation of Samples for iTRAQ Labeling and Strong Cation Exchange}

A Seppro Bovine Serum Albumin depletion kit (Sigma Aldrich, St. Louis, MO) was used to remove albumin from the blood (Faulkner et al., 2011). Following removal of albumin, plasma was concentrated and a Vivaspin 2 centrifugal concentrator (Sartorius Stedim Biotech, Göttingen, Germany) was used to exchange the buffer with a $3-\mathrm{kDa}$ cut-off into $0.5 \mathrm{M}$ triethylammonium bicarbonate. Protein denaturation, reduction, and alkylation were performed according to a previous study (Li et al., 2014). Strong cation-exchange chromatography was performed according to the methods previously described (Geng et al., 2015).

\section{Protein Identification and Quantification}

The automated software IQuant (http://sourceforge .net/projects/iquant/) was applied to quantify the labeled peptides with isobaric tags. The peptides and mass spectra were prefiltered at a false discovery rate (FDR) of $1 \%$ to evaluate the confidence of identified peptides. Based on the parsimony principle, identified peptide sequences were assembled into a set of confident proteins. A reverse database search method was applied to estimate the FDR of $1 \%$ for unique protein peptide identification. All proteins or peptides were identified with a strict cutoff unused prot score of $>1.3$ (corresponds to $>95 \%$ confidence) as the qualification criterion. A cutoff point at $50 \%$ variation and foldchange $(\mathbf{F C})>1.2$ or $<0.8$ within an error factor $<2$ was applied to identify differentially expressed proteins (DEP) between the samples of the 2 groups.

\section{Total RNA Extraction and Analysis of miRNA High- Throughput Sequencing}

Total RNA was extracted from the plasma of the same animals used for the proteome analysis with TRIzol reagent (Invitrogen), and purified according to the manufacturer's protocol of a mirVana miRNA Isolation Kit (Ambion, Austin, TX). Library establishment and Illumina sequencing (Illumina Inc., San Diego, CA) were conducted in accordance with the preparation protocol for Illumina small RNA samples (Lopez et al., 2015). Analysis of the raw data of Illumina sequencing was based on a previous study (Yusuf et al., 2015). Unique reads between 18 and 25 nt were selected from the raw data to perform further analysis. The miRNA expression level in a sample was standardized to obtain the transcripts reads per million (TPM) values with the following formula: $\mathrm{TPM}=1,000,000 \times(\mathrm{miRNA}$ mapped reads)/(total mapped reads) (Yu et al., 2015). The $\mathrm{R}$ package EdgeR was used to analyze expression level of miRNA (Robinson et al., 2010), and EdgeR was based on the negative binomial distribution model. MicroRNAs with a $P$-value $\leq 0.05$ and $\mathrm{FC} \geq 2$ were considered upregulated, whereas those with a $P$-value $\leq 0.05$ and $\mathrm{FC} \leq 0.5$ were considered downregulated.

\section{Bioinformatics Analysis}

Blast2Go 4.0.7 software (Lin et al., 2013) was used to classify the biological processes of gene ontology (GO) for a better understanding of the biological functions of differentially expressed miRNAs and proteins in accordance with a previous description (Ji et al., 2017).

Furthermore, Ingenuity Pathway Analysis (IPA) software (version 9.0; Qiagen Bioinformatics, Redwood City, CA) was used to identify related biological functions and major canonical pathways (Geng et al., 2015). In brief, a data set including the DEP and corresponding extreme values of expression was uploaded into the "Dataset Files" of IPA. These proteins were then processed by core analysis in IPA. The canonical pathways obtained in the present work were selected based on the Fisher's exact test $P$-value from the IPA library. The importance of the relationship between the DEP and canonical pathways was evaluated as previously 
described (Kulkarni et al., 2010; Krämer et al., 2014). In the present work, pathways with $P$-values $<0.05$ were considered significant in Jersey cattle exposed to HAH. Additionally, a miRNA regulatory network was established to explore the interaction networks between miRNAs and their target genes (Geng et al., 2014).

\section{Statistical Analysis}

Differential analysis of the expression level of miRNA was conducted by using the $\mathrm{R}$ package edgeR (Robinson et al., 2010), and significant $P$-value and $\mathrm{FC}$ values were used as the evaluation criteria for differential expression. $P$-value $\leq 0.05$ and $\mathrm{FC} \geq 2\left[\log _{2}(\mathrm{FC}) \geq\right.$ 1] were considered to indicate upregulated expression, whereas $P$-value $\leq 0.05$ and $\mathrm{FC} \leq 0.5\left[\log _{2}(\mathrm{FC}) \leq-1\right]$ were considered to indicate downregulated expression.

The software IQuant was used to quantify the labeled peptides with isobaric tags. To assess the confidence of peptides, the PSM were prefiltered at a PSM level FDR of $1 \%$. To control the rate of false-positives at the protein level, a protein FDR at $1 \%$, based on the picked protein FDR strategy, was also estimated after protein inference. Proteins with differential abundance among the 2 groups were considered when $\mathrm{FC} \geq 1.2$ or $\leq 0.8$ and $P$-value $<0.05 ; P$-values between groups were calculated using a $t$-test (independent, 2-tailed, unequal variance). Differences in serum antibody and cytokine levels was measured by an independent-samples $t$-test.

\section{RESULTS}

\section{Serum Antibody and Cytokine Levels}

As shown in Table 2, the level of IgM increased $(P$ $<0.05)$ and those of cytokine IL-2, IL-6, and TNF- $\alpha$ decreased $(P<0.05)$ in HAH-stressed Jersey cattle compared with HAH-free Jersey cattle. The differences in the levels of $\operatorname{IgG}$ and $\operatorname{IgA}$ were not significant $(P$ $>0.05$ ) between HAH-stressed and HAH-free Jersey cattle.

\section{Differentially Expressed miRNAs, Protein Profiles, and Target Proteins}

In the present work, we applied miRNA microarray analysis to identify differential expression of miRNAs from HAH-stressed and HAH-free Jersey cattle. Among the 468 miRNAs found in the microarray, 25 were upregulated with $\mathrm{FC}>2$, and 22 were downregulated with FC $<0.5$ in HAH-stressed Jersey cattle, with $P<0.05$ as the first screening criterion, compared with $\mathrm{HAH}-$ free Jersey cattle (Supplemental Table S1; https://doi .org/10.3168/jds.2018-15515).

An iTRAQ-based LC-MS/MS quantitative proteomics approach was selected to explore the effects of $\mathrm{HAH}$ on plasma protein profiles. In total, 854 proteins were identified based on a standard FDR of 1\%. Differentially expressed proteins were selected by the criterion of a minimum $\mathrm{FC}>1.2$ (upregulated) and maximum FC $<0.8$ (downregulated) without Student's $t$-test or other statistical analysis (Lu et al., 2008). A total of 264 DEP (127 upregulated and 137 downregulated) were identified between the HAH-stressed group and HAH-free group. The characteristics and descriptions of DEP are shown in Supplemental Table S2 (https:// doi.org/10.3168/jds.2018-15515).

The data of miRNA-protein pairs obtained from the IPA software were analyzed, and 6 miRNAs targeting 45 proteins of HAH-stressed Jersey cattle were predicted. Networks of the interactions between miRNAs and target proteins are shown in Figure 1. The IPA results

Table 2. Effects of high-altitude hypoxia $(\mathrm{HAH})$ on the concentrations of serum immunoglobulins and cytokines in HAH-stressed Jersey cattle $(\mathrm{n}=6)$

\begin{tabular}{lrrrr}
\hline & \multicolumn{2}{c}{ Group $^{1}$} & & \\
\cline { 2 - 3 } Item & Shenyang & Nyingchi & SEM & $P$-value \\
\hline Immunoglobulins & & & & \\
IgM $(\mu \mathrm{g} / \mathrm{mL})$ & 457.68 & 233.69 & 16.771 & 0.001 \\
IgG $(\mu \mathrm{g} / \mathrm{mL})$ & $2,565.76$ & $2,639.97$ & 47.978 & 0.153 \\
IgA $(\mu \mathrm{g} / \mathrm{mL})$ & 420.32 & 397.66 & 18.042 & 0.254 \\
Cytokines & & & \\
IL-2 $(\mathrm{ng} / \mathrm{L})$ & 0.31 & 0.17 & 0.032 & 0.002 \\
IL-6 $(\mathrm{ng} / \mathrm{L})$ & 1.54 & 0.10 & 0.013 & 0.001 \\
TNF- $\alpha^{2}(\mathrm{ng} / \mathrm{L})$ & & 1.09 & 0.093 & 0.004 \\
\hline
\end{tabular}

${ }^{1}$ Shenyang = Jersey cattle fed for $30 \mathrm{~d}$ in Shenyang, China (50 m above sea level; HAH-free group); Nyingchi $=$ Jersey cattle fed for $30 \mathrm{~d}$ in Nyingchi, Tibet (3,000 m above sea level; HAH group); blood was collected on the last day of the experiment from animals in both groups.

${ }^{2}$ Tumor necrosis factor- $\alpha$. 
revealed that the most affected diseases and functions in adaptation to HAH included endocrine system disorders, organismal injury and abnormalities, cardiovascular disease, dermatological diseases and conditions, inflammatory disease and inflammatory response, among others. Further analysis showed that the miRNAs and their targets in the interaction networks were mainly involved in the acute phase response (APR) signaling, liver X receptor/retinoid X receptor $(\mathbf{L X R} / \mathbf{R X R})$ activation pathways, coagulation system, and complement system. Therefore, we inferred that 6 miRNAs synergistically regulated the adaptation to $\mathrm{HAH}$ in Jersey cattle, primarily through the above-mentioned signaling pathways.

\section{Gene Ontology and Functional and Pathway Analyses}

Gene ontology enrichment was performed for functional analysis of the 264 differential proteins and 47 differential miRNAs. The results were categorized into the "biological processes," "cellular components," and "molecular functions" classes. The top 20 biological processes of the GO enrichment analysis of differential proteins and miRNAs are shown in Figure 2. The GO analysis confirmed that the DEP were overwhelmingly associated with stress response, immune response, and complement activation (Table 3), whereas the differentially expressed miRNAs were overwhelmingly associated with localization, signal transduction, and response to stimulus.

The canonical pathways of integrative analysis obtained from the IPA software are shown in Figure 3. In the pathway analysis, we found the top 4 statistically significant enriched canonical pathways based on the $-\log (P$-value $)$ associated with the 73 deregulated plasma proteins of Jersey cattle (Table 3). Among these pathways, the top 4 according to $P$-value were APR signaling (21 proteins: SERPINA1, HPX, A2M, AHSG, APOH, TF, RBP4, SERPINF1, ALB, ITIH3, ITIH4, SERPINA3, ITIH2, HRG, APOA1, SAA4, C9, CPB, F2, HP, and CFB), LXR/RXR activation (19 proteins: LPL, LCAT, SAA1, APOA4, CLU, APOE, CD14, APOC2, PLTP, VTN, LBP, A1BG, APOH, IL1RAP, GC, TTR, APOF, ITIH4, and C9), coagulation system (17 proteins: F13A1, VWF, SERPIND1, F10, SERPINA5, F13B, F7, SERPINC1, F5, FGG, FGB, F11, KLKB1, F12, KNG1, F2, and SERPINA1), and complement system (16 proteins: CD59, C1QC, C1S, C5, C8A, C7, CFH, C8B, C6, C1QA, CFI, C2, MBL2, CFD, C9, and CFB). The top $4-\log (P$-value $)$ pathways corresponding to APR signaling, LXR/RXR activation, coagulation system, and complement system in plasma had different $\mathrm{z}$-scores $(\mathrm{z}=-0.125, \mathrm{z}=$
$1.134, \mathrm{z}=-0.943$, and $\mathrm{z}=-0.632$, respectively). The complement and coagulation cascade network pathways are shown schematically in Figure 4, and the proteins involved in these pathways are listed in Table 3.

\section{DISCUSSION}

Plasma contains all the information derived from cells and tissues of animal body and it is therefore regarded as a determinant of health status (Zhang et al., 2007). Application of plasma proteomics and miRNA analysis contributes to diagnostic and prognostic information. In this work, 6 differentially expressed miRNAs and 73 DEP were associated with adaptation to HAH in Jersey cattle. Four canonical pathways, based on their value of $-\log (P$-value $)$, were identified as enriched in APR signaling, LXR/RXR activation, complement system, and coagulation system.

A previous study showed that $\mathrm{HAH}$ influences the function of the immune system, increasing the vulnerability to infection and disease (Mishra and Ganju, 2010). High-altitude hypoxia can decrease the release of cytokines and variably affect immunoglobulin secretion at different altitudes and durations (Mishra and Ganju, 2010). In the present study, the level of serum $\operatorname{IgM}$ decreased significantly, whereas levels of $\operatorname{IgG}$ and IgA were not significantly changed. These results are consistent with the statement of Mishra et al. (2015) that chronic stress can suppress immunity. Studies have found that hypoxia causes decreased levels of the cytokines IL-2 and IL-6 (Yang et al., 2009; Zhao and Zhao, 2013). However, TNF- $\alpha$ levels decrease after 4 wk in high-altitude areas (Mishra and Ganju, 2010), consistent with results in the present work.

MicroRNA miR-155-5p is a multifunctional miRNA that plays an important role in the regulation of immune response (Faraoni et al., 2009), and it is a necessary factor for the immune response of lymphocytes in the body (Rodriguez et al., 2007). Studies show that miR-155 affects the functions of T-helper (Th) 1 and Th2 cells and as a regulatory factor in the activation of T cells (Ferrajoli et al., 2013; Li et al., 2013b). Additionally, miR-155-5p is involved in T-cell inflammation, and its expression is closely related to inflammatory stimulating factors (Thai et al., 2007). In the integrated network of this paper, phosphatidylinositol-3,4,5trisphosphate 5-phosphatase 1 (INPP5D) was targeted by miR-155-5p, and INPP5D is also a negative regulator of B-cell receptor (BCR) signaling in B cells (Cui et al., 2014). Therefore, we deduced that miR-155-5p regulated the immune response of $\mathrm{B}$ cells by targeting INPP5D to adapt to HAH stress in Jersey cattle.

MicroRNA miR-17-5p belongs to the Mir-17-92 gene cluster, which regulates the normal development of im- 

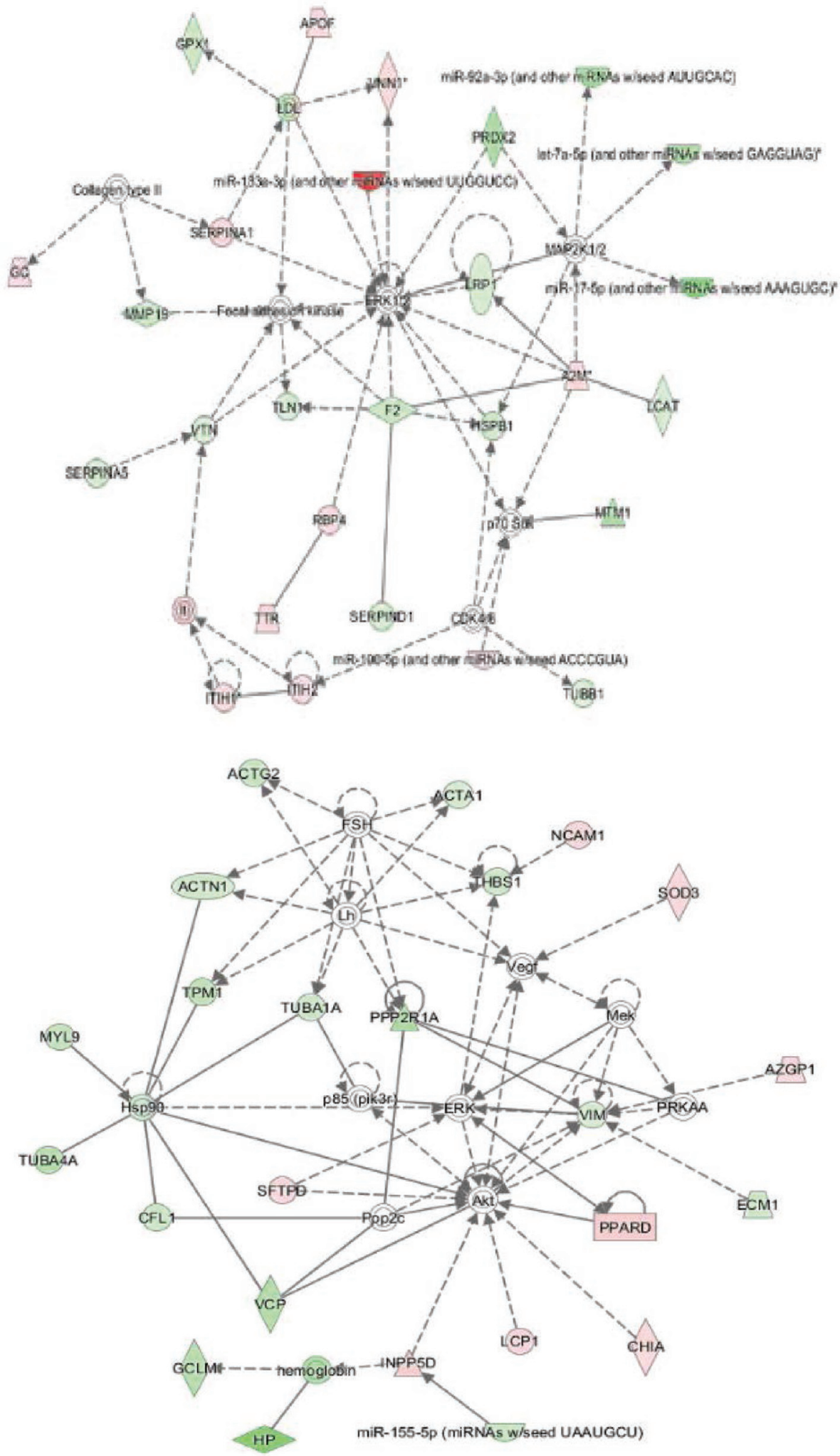

Figure 1. An interaction network of the micro(mi)RNAs and their targets in the plasma of high-altitude hypoxia-stressed Jersey cattle. Ingenuity Pathway Analysis software (Qiagen Bioinformatics, Redwood City, CA) was used to generate the interaction networks of miR-133a-3p, miR-92-3p, miR-17-5p, let-7a-5p, miR-100-5p, miR-155-5P, and their targets. Each node indicates a single protein or miRNA. Red indicates upregulated miRNAs, and green indicates downregulated proteins. Lines and arrows indicate connections between 2 objects; broken lines indicate indirect relationships, and solid lines indicate direct relationships. 
mune organs and the immune response to pathogenic infection (Cox et al., 2010; Kang et al., 2013; Poitz et al., 2013). In previous studies, miR-17 was shown to be upregulated in peripheral blood $\mathrm{T}$ cells in patients with illness caused by HAH (Simpson et al., 2014; Schoene, 2008). Additionally, miR-17 can regulate the inflammatory response by promoting Th1 reaction and inhibiting T-cell differentiation (Kuo et al., 2019). In the present
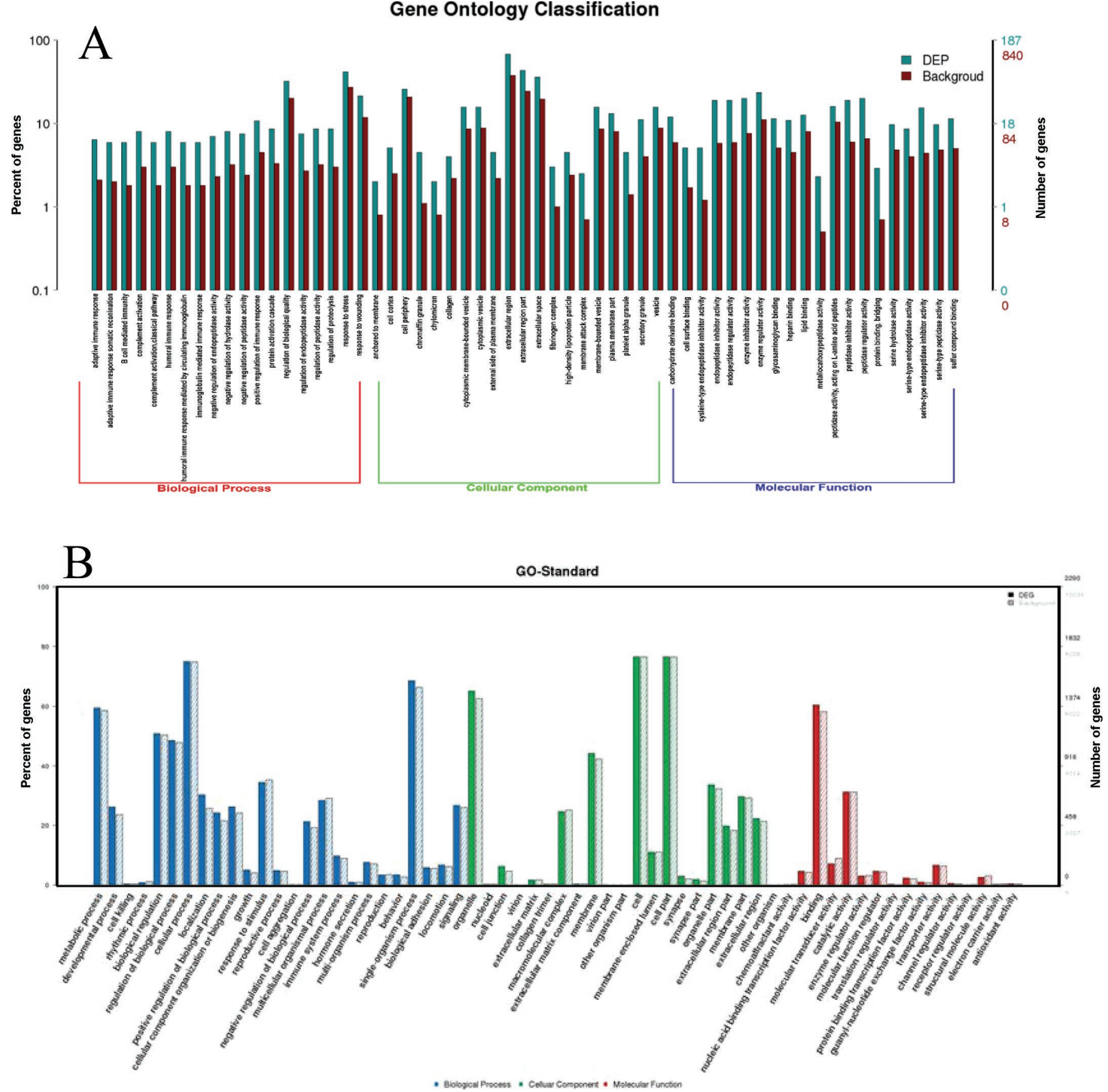

Figure 2. Gene ontology (GO) classification diagram of (A) differentially expressed proteins (DEP) and (B) micro(mi)RNA. The x-axis shows the classification name of the GO annotation information, the left y-axis shows the percentage of the number of proteins or genes, and the right $\mathrm{y}$-axis indicates the number of proteins or genes. The solid line spline shows the GO annotation information of the protein or target gene of a miRNA with differential expression, and the dotted line spline shows that of a protein or gene in the $3^{\prime}$ untranslated region (or mRNA) database. 
Table 3. Differentially expressed proteins in the plasma of Jersey cattle exposed to high-altitude hypoxia (HAH) associated with complement and coagulation caspases, immune network, response to stress, and LXR/RXR ${ }^{1}$ activation

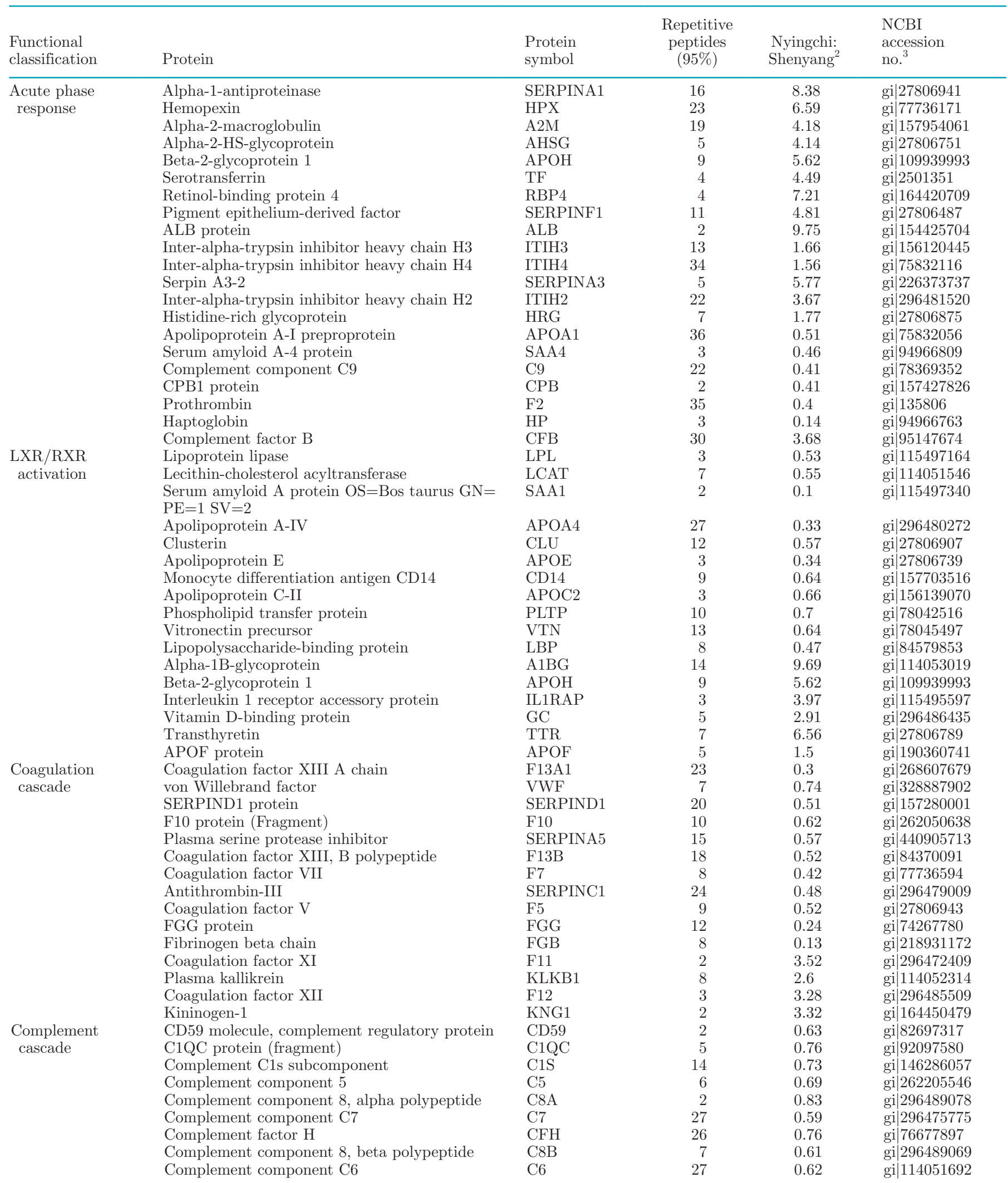


Table 3 (Continued). Differentially expressed proteins in the plasma of Jersey cattle exposed to high-altitude hypoxia (HAH) associated with complement and coagulation caspases, immune network, response to stress, and LXR/RXR ${ }^{1}$ activation

\begin{tabular}{|c|c|c|c|c|c|}
\hline $\begin{array}{l}\text { Functional } \\
\text { classification }\end{array}$ & Protein & $\begin{array}{l}\text { Protein } \\
\text { symbol }\end{array}$ & $\begin{array}{c}\text { Repetitive } \\
\text { peptides } \\
(95 \%)\end{array}$ & $\begin{array}{l}\text { Nyingchi: } \\
\text { Shenyang }\end{array}$ & $\begin{array}{l}\text { NCBI } \\
\text { accession } \\
\text { no. }{ }^{3}\end{array}$ \\
\hline & Complement $\mathrm{C} 1 \mathrm{q}$ subcomponent subunit A & C1QA & 6 & 0.69 & gi|62460582 \\
\hline & Complement C2 & $\mathrm{C} 2$ & 10 & 3.83 & gi|77735935 \\
\hline & Mannose-binding protein $\mathrm{C}$ & MBL2 & 5 & 2.54 & gi 27806549 \\
\hline & Complement factor D & CFD & 6 & 1.48 & gi| 77735465 \\
\hline
\end{tabular}

${ }^{1}$ Liver X receptor/retinoid X receptor.

${ }^{2}$ Ratio of HAH-stressed (Nyingchi, Tibet; 3,000 m above sea level) to HAH-free (Shenyang, China; $50 \mathrm{~m}$ above sea level) cattle.

${ }^{3}$ National Center for Biotechnology Information (https://www.ncbi.nlm.nih.gov/).

study, miR-17-5p was upregulated in HAH-stressed Jersey cattle. Therefore, we conjectured that miR-175 p might play a key role in regulating the development of immune organs and the immune response to adapt to the stress when exposed to HAH in Jersey cattle.

From the results of the integrative analysis using the IPA software, the APR signaling pathway was downregulated (based on the negative $\mathrm{z}$-score; $\mathrm{z}=-0.125$ ).
The APR is involved in multiple biological processes that protect the organism from local or systemic stimuli during inflammatory processes (Ceciliani et al., 2002). In these processes, tissue damage induced by inflammation is usually accompanied by the release of proinflammatory cytokines, which help regulate the synthesis of the acute-phase reactants in liver (Ramírez-Tejero et al., 2018). A previous study found that stressors acti-

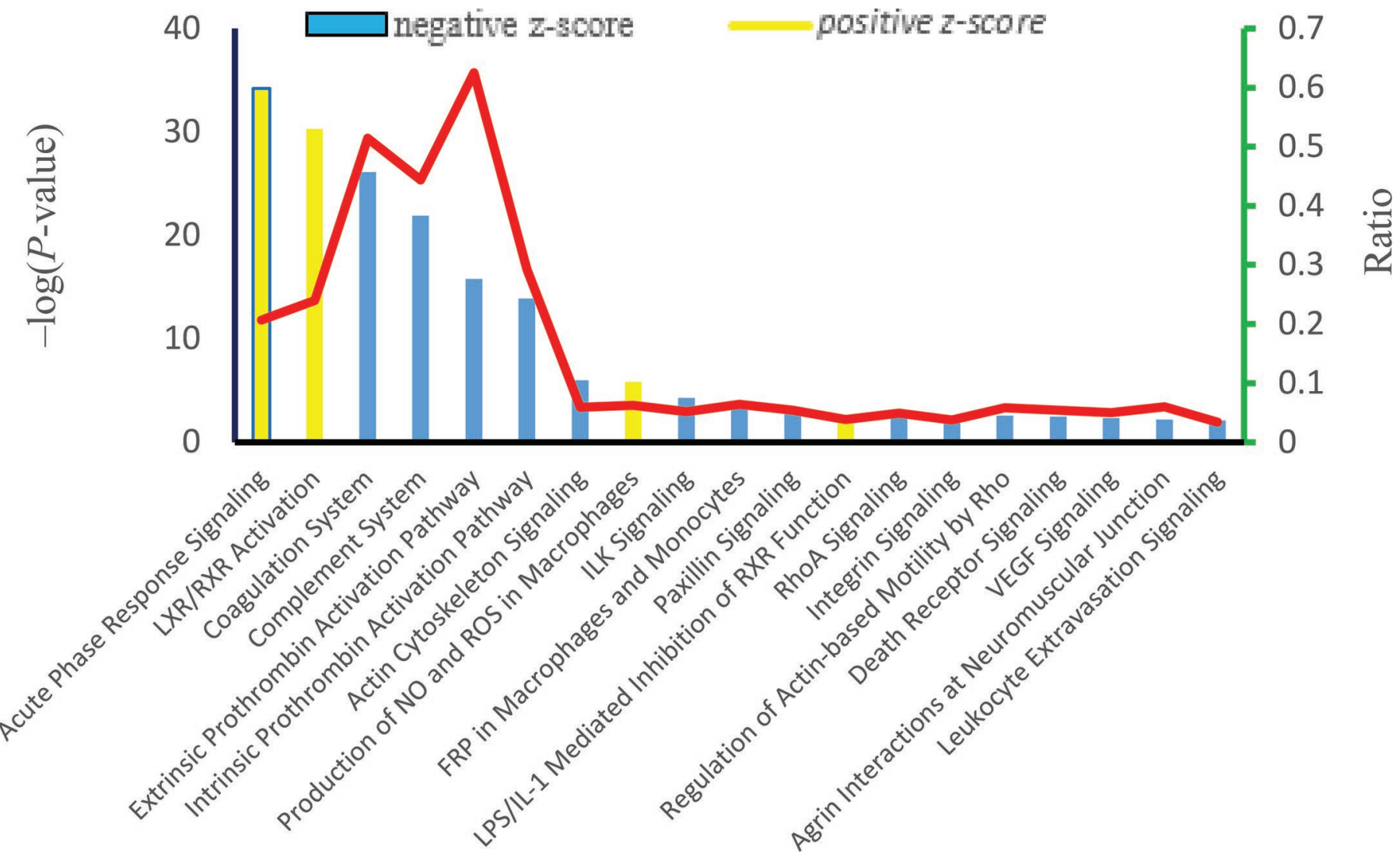

Figure 3. Canonical pathways enriched in Jersey cattle exposed to high-altitude hypoxia by integrative analysis. Orange and blue indicate positive and negative z-scores, respectively. LXR/RXR = liver X receptor/retinoid X receptor; $\mathrm{NO}=$ nitric oxide; ROS $=$ reactive oxygen species; ILK = integrin-linked kinase; FRP = Fc $\gamma$ receptor-mediated phagocytosis; RhoA = Ras homolog gene family, member A; VEGF = vascular endothelial growth factor. 


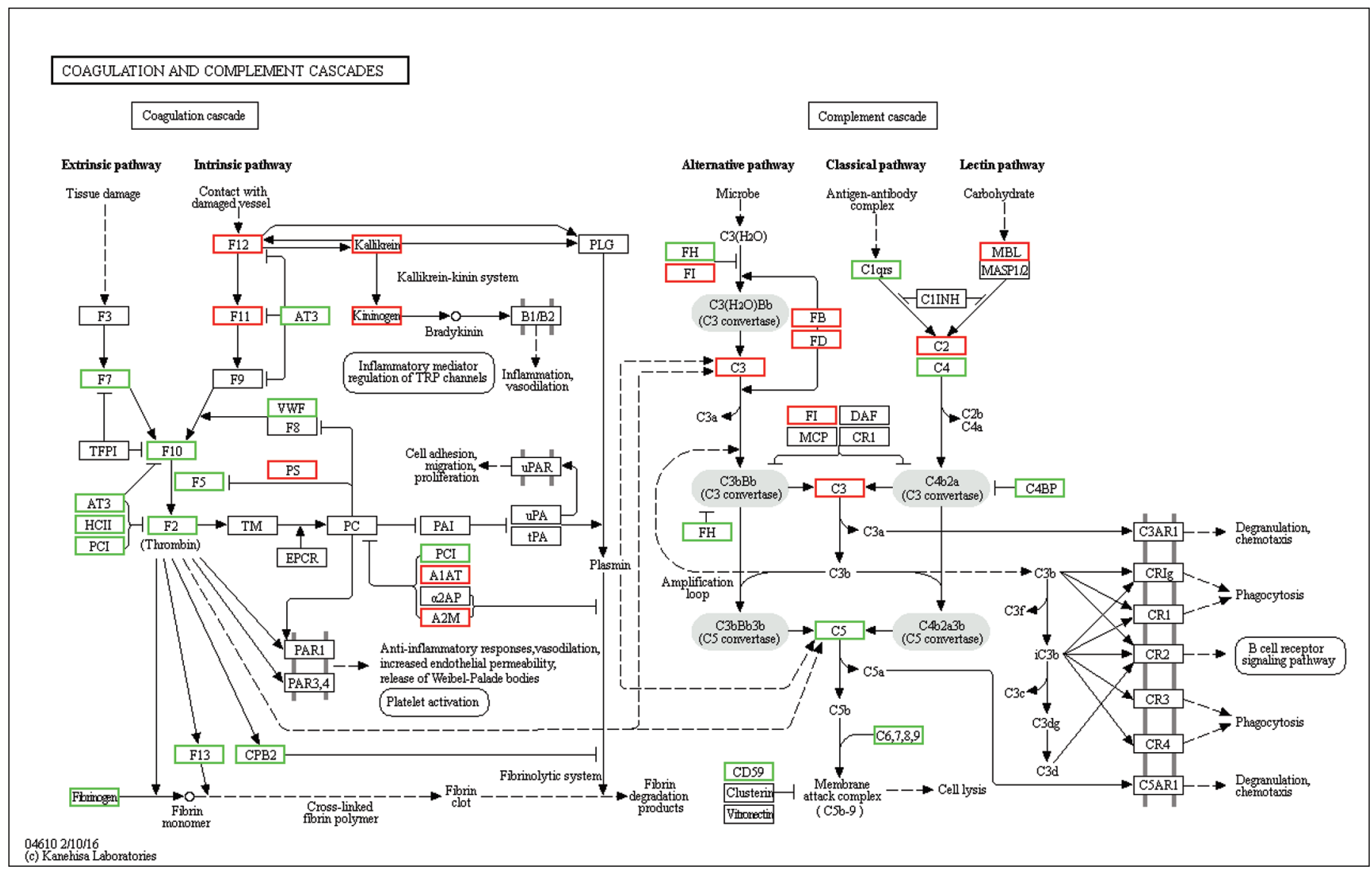

Figure 4. Network pathway of identified plasma proteins in the coagulation and complement cascades that were differentially expressed in high-altitude hypoxia (HAH)-stressed and $\mathrm{HAH}$-free Jersey cattle. Upregulated and downregulated proteins are marked with red and green borders, respectively. Proteins involved in this pathway are listed in Table 2.

vating the APR induced the release of cytokines IL-6 and TNF- $\alpha$ (Cray et al., 2009), which was consistent with the decrease in IL-2, IL-6, and TNF- $\alpha$ after $4 \mathrm{wk}$ of exposure to HAH in this study. The APR is a systemic immune-mediated response associated with increased levels of serum amyloid A, ceruloplasmin, haptoglobin, $\alpha 1$-acid glycoprotein, and $\alpha$-2-macroglobulin and decreased levels transferrin, apolipoprotein A, and albumin (Lakota et al., 2011). In the present work, the expression of ceruloplasmin, $\alpha-2$-macroglobulin, and $\alpha-1$-acid glycoprotein was upregulated, whereas expression of transferrin, serum albumin, serum amyloid A, apolipoprotein A, and haptoglobin was downregulated, which led to the downregulation of the APR signaling pathway.

The integrative analysis also identified the significantly enriched LXR/RXR activation pathway, which is associated with cholesterol transport, glucose metabolism, and modulation of inflammatory responses (A-Gonzalez and Castrillo, 2011; Zelcer and Tontonoz, 2006). In previous studies, LXR inhibit inflammation
(Joseph et al., 2003; Terasaka et al., 2005), which might be conducted through competition for transcriptional coactivators (Castrillo et al., 2003a) and inhibition of nuclear factor- $\kappa \mathrm{B}$ (Castrillo et al., 2003b). In recent studies, microbial pathogens accelerated lesion development by disturbing LXR-dependent cholesterol metabolism (Castrillo et al., 2003a). The lack of LXR increases vulnerability to intracellular pathogens (Joseph et al., 2004). In the present study, the LXR/RXR activation pathway was upregulated ( $\mathrm{z}$-score $=0.24$ ), which was consistent with the statement above.

The complement system was identified as one of the top 4 canonical pathways in this study. High-altitude hypoxia can diminish the function of the immune system, whereas neutrophils and macrophages can quickly adapt their metabolic activity when exposed to hypoxia (Mishra and Ganju, 2010; Bosco et al., 2011). The influence of $\mathrm{HAH}$ on the immune system primarily involves changes in $\mathrm{T}$ cells, humoral response (B cells), natural killer cell cytotoxicity, cytokine profile, and phagocytosis (Mishra and Ganju, 2010). However, 
the actual mechanism involved in the altered immune function under $\mathrm{HAH}$ remains unclear, particularly for changes in the complement system under HAH stress. As a primary effector response to the immune system, the complement system can induce various mechanisms of immunoregulation (Hovhannisyan et al., 2010) and plays an important role not only in innate immunity and adaptive immunoregulation, but also in resistance to infection (Carroll, 2008). In this work, complement components $\mathrm{C} 1, \mathrm{C} 4, \mathrm{C} 5, \mathrm{C} 6, \mathrm{C} 7, \mathrm{C} 8, \mathrm{C} 9$, and complement factor $\mathrm{H}$ were downregulated when exposed to HAH stress (Table 2). Animals lacking various complement components show different phenotypes associated with host defense, including being more susceptible to infection, impaired response to $\mathrm{T}$ and $\mathrm{B}$ cells, reduced phagocytic activity, and weakened ability to remove pathogens and other immune complexes (Dunkelberger and Song, 2010). Therefore, we concluded that $\mathrm{HAH}$ decreased the level of complement components in plasma, which might result from impaired immune function involved in innate and adaptive immunity in Jersey cattle exposed to HAH.

Generally, complement cascades are accompanied by interactions of coagulation cascades (Markiewski et al., 2007; Amara et al., 2010). Amara et al. (2010) found that factors of the coagulation system (thrombin, coagulation factors XI, X, and IX) are connected to the central complement components C3 and C5 in vitro and in vivo, as shown in Figure 4.

\section{CONCLUSIONS}

In summary, because all of the biological pathways involved in this integrative analysis were related to inflammation and immune response, we point to these as being crucial in the adaptation to HAH in Jersey cattle. The activation of LXR/RXR could alleviate inflammation. Therefore, we deduced that Jersey cattle under HAH stress might adapt through regulation of inflammatory homeostasis by inhibiting the acute phase response, coagulation system, and complement system and promoting LXR/RXR activation.

\section{ACKNOWLEDGMENTS}

The Ministry of Science and Technology of the People's Republic of China (2018YFD0501604, 2017YFD0500500; Beijing), China Hunan Provincial Science and Technology Department (2017NK1020, 2017JJ1028, 2013TF3006; Changsha), National Natural Science Foundation of China (No. 31772632, 31372342; Beijing), Youth Innovation Team Project of ISA, CAS (2017QNCXTD_ZCS; Changsha), and Special Finance Project of Tibet autonomous region (XZNKY-
2018-C-030; Lhasa) supported this work. Authors CZ, $\mathrm{ZK}, \mathrm{BL}$, and ZT designed the research; ZK, AR, LC, and $\mathrm{HJ}$ conducted the research; ZK and CZ analyzed the data; and ZK, CZ, JJ, and ZT wrote the paper; ZK and $\mathrm{CZ}$ had primary responsibility for the final content. All authors read and approved the final manuscript.

\section{REFERENCES}

A-Gonzalez, N., and A. Castrillo. 2011. Liver X receptors as regulators of macrophage inflammatory and metabolic pathways. Biochim. Biophys. Acta 1812:982-994.

Amara, U., M. A. Flierl, D. Rittirsch, A. Klos, H. Chen, B. Acker, U. B. Brückner, B. Nilsson, F. Gebhard, J. D. Lambris, and M. Huber-Lang. 2010. Molecular intercommunication between the complement and coagulation systems. J. Immunol. 185:5628-5636.

Baek, D., J. Villen, C. Shin, F. D. Camargo, S. P. Gygi, and D. P. Bartel. 2008. The impact of microRNAs on protein output. Nature 455:64-71.

Bhende, M. P., A. P. Karpe, and B. P. Pal. 2013. High altitude retinopathy. Indian J. Ophthalmol. 61:176-177.

Bosco, M. C., D. Pierobon, F. Blengio, F. Raggi, C. Vanni, M. Gattorno, A. Eva, F. Novelli, P. Cappello, M. Giovarelli, and L. Varesio. 2011. Hypoxia modulates the gene expression profile of immunoregulatory receptors in human mature dendritic cells: Identification of TREM-1 as a novel hypoxic marker in vitro and in vivo. Blood 117:2625-2639.

Carroll, M. C. 2008. Complement and humoral immunity. Vaccine 26:I28-I33.

Castrillo, A., S. B. Joseph, C. Marathe, D. J. Mangelsdorf, and P. Tontonoz. 2003a. Liver X receptor-dependent repression of matrix metalloproteinase-9 expression in macrophages. J. Biol. Chem. 278:10443-10449.

Castrillo, A., S. B. Joseph, S. A. Vaidya, M. Haberland, A. M. Fogelman, G. Cheng, and P. Tontonoz. 2003b. Crosstalk between LXR and toll-like receptor signaling mediates bacterial and viral antagonism of cholesterol metabolism. Mol. Cell 12:805-816.

Ceciliani, F., A. Giordano, and V. Spagnolo. 2002. The systemic reaction during inflammation: the acute-phase proteins. Protein Pept. Lett. 9:211-223.

Cox, M. B., M. J. Cairns, K. S. Gandhi, A. P. Carroll, S. Moscovis, G. J. Stewart, S. Broadley, R. J. Scott, D. R. Booth, and J. Lechner-Scott. 2010. MicroRNAs miR-17 and miR-20a inhibit T cell activation genes and are under-expressed in MS whole blood. PLoS One 5:e12132.

Cray, C., J. Zaias, and N. H. Altman. 2009. Acute phase response in animals: a review. Comp. Med. 59:517-526.

Cui, B., L. G. Chen, S. P. Zhang, M. Mraz, J. F. Fecteau, J. Yu, E. M. Ghia, L. Zhang, L. Bao, L. Z. Rassenti, K. Messer, G. A. Calin, C. M. Croce, and T. J. Kipps. 2014. MicroRNA-155 influences B-cell receptor signaling and associates with aggressive disease in chronic lymphocytic leukemia. Blood 124:546-554.

Dunkelberger, J. R., and W. C. Song. 2010. Complement and its role in innate and adaptive immune responses. Cell Res. 20:34-50.

Dymacek, J., B. N. Snyder-Talkington, D. W. Porter, M. G. Wolfarth, V. Castranova, Y. Qian, and N. L. Guo. 2015. mRNA and miRNA regulatory networks reflective of multi-walled carbon nanotubeinduced lung inflammatory and fibrotic pathologies in mice. Toxicol. Sci. 144:51-64.

Faraoni, I., F. R. Antonetti, J. Cardone, and E. Bonmassar. 2009. miR-155 gene: A typical multifunctional microRNA. Biochim. Biophys. Acta 1792:497-505.

Faulkner, S., G. Elia, M. Hillard, P. O'Boyle, M. Dunn, and D. Morris 2011. Immunodepletion of albumin and immunoglobulin $\mathrm{G}$ from bovine plasma. Proteomics 11:2329-2335.

Ferrajoli, A., T. D. Shanafelt, C. Ivan, M. Shimizu, K. G. Rabe, N. Nouraee, M. Ikuo, A. K. Ghosh, S. Lerner, L. Z. Rassenti, L. C. Xiao, J. H. Hu, J. M. Reuben, S. Calin, M. James You, J. T. Manning, W. G. Wierda, Z. Estrov, S. O'Brien, T. J. Kipps, M. J. Ke- 
ating, N. E. Kay, and G. A. Calin. 2013. Prognostic value of miR155 in individuals with monoclonal B-cell lymphocytosis and patients with B chronic lymphocytic leukemia. Blood 122:1891-1899.

Fukunaga, S., A. Kakehashi, K. Sumida, M. Kushida, H. Asano, M. Gi, and H. Wanibuchi. 2015. Integrative analyses of miRNA and proteomics identify potential biological pathways associated with onset of pulmonary fibrosis in the bleomycin rat model. Toxicol. Appl. Pharmacol. 286:188-197.

Geng, X., G. Wang, Y. Qin, X. Zang, P. Li, Z. Geng, D. Xue, Z. Dong, K. Ma, G. Chen, and C. Xu. 2015. iTRAQ-based quantitative proteomic analysis of the initiation of head regeneration in planarians. PLoS One 10:e0132045.

Geng, X., T. Xu, Z. Niu, X. Zhou, L. Zhao, Z. Xie, D. Xue, F. Zhang, and C. Xu. 2014. Differential proteome analysis of the cell differentiation regulated by BCC, CRH, CXCR4, GnRH, GPCR, IL1 signaling pathways in Chinese fire-bellied newt limb regeneration. Differentiation 88:85-96.

Gou, X., Z. Wang, N. Li, F. Qiu, Z. Xu, D. W. Yan, S. L. Yang, J. Jia, X. Y. Kong, Z. H. Wei, S. X. Lu, L. S. Lian, C. X. Wu, X. Y. Wang, G. Z. Li, T. Ma, Q. Jiang, X. Zhao, J. Q. Yang, B. H. Liu, D. K. Wei, H. Li, J. F. Yang, Y. L. Yan, G. Y. Zhao, X. X. Dong, M. L. Li, W. D. Deng, J. Leng, C. C. Wei, C. Wang, H. M. Mao, H. Zhang, G. H. Ding, and Y. X. Li. 2014. Whole genome sequencing of six dog breeds from continuous altitudes reveals adaption to high-altitude hypoxia. Genome Res. 24:1308-1315.

Hanada, S., A. Kakehashi, N. Nishiyama, M. Wei, S. Yamano, K. Chung, H. Komatsu, H. Inoue, S. Suehiro, and H. Wanibuchi. 2013. Myristoylated alanine-rich C-kinase substrate as a prognostic biomarker in human primary lung squamous cell carcinoma. Cancer Biomark. 13:289-298.

Hendrickson, S. L. 2013. A genome wide study of genetic adaptation to high altitude in feral Andean Horses of the páramo. BMC Evol. Biol. 13:273.

Hotta, J., M. Hanaoka, Y. Droma, Y. Katsuyama, M. Ota, and T. Kobayashi. 2004. Polymorphisms of renin-angiotensin system genes with high-altitude pulmonary edema in Japanese subjects. Chest 126:825-830.

Hovhannisyan, L. P., G. M. Mkrtchyan, S. H. Sukiasian, and A. S. Boyajyan. 2010. Boyajyan, Alterations in the complement cascade in post-traumatic stress disorder. Allergy Asthma Clin. Immunol. $6: 3$.

Hu, N. X., and N. H. Hu. 2015. Effects of cold strike and freeze damage on isolated sperm from bulls of different species at high altitude. Chin. Dairy. Cattl. 9:23-26.

Huang, T. C., S. M. Pinto, and A. Pandey. 2013. Proteomics for understanding miRNA biology. Proteomics 13:558-567.

Huerta-Sánchez, E., X. Jin, Z. Bianba, B. M. Peter, N. Vinckenbosch, Y. Liang, X. Yi, M. He, M. Somel, and P. Ni. 2014. Altitude adaptation in Tibetans caused by introgression of Denisovanlike DNA. Nature 512:194-197.

Ji, X., X. Liu, Y. Peng, R. Zhan, H. Xu, and X. Ge. 2017. Comparative analysis of methicillin-sensitive and resistant Staphylococcus aureus exposed to emodin based on proteomic profiling. Biochem. Biophys. Res. Commun. 494:318-324.

Joseph, S. B., M. N. Bradley, A. Castrillo, K. W. Bruhn, P. A. Mak, L. Pei, J. Hogenesch, R. M. O'connell, G. Cheng, E. Saez, J. F. Miller, and P. Tontonoz. 2004. LXR-dependent gene expression is important for macrophage survival and the innate immune response. Cell 119:299-309.

Joseph, S. B., A. Castrillo, B. A. Laffitte, D. J. Mangelsdorf, and P. Tontonoz. 2003. Reciprocal regulation of inflammation and lipid metabolism by liver X receptors. Nat. Med. 9:213-219.

Kang, S. G., W. H. Liu, P. W. Lu, H. Y. Jin, H. W. Lim, J. Shepherd, D. Fremgen, E. Verdin, M. B. A. Oldstone, H. Qi, J. R. Teijaro, and C. C. Xiao. 2013. MicroRNAs of the miR-17 / 92 family are critical regulators of $\mathrm{T}(\mathrm{FH})$ differentiation. Nat. Immunol. 14:849-857.

Kapoor, S. 2013. High-altitude ophthalmic changes: An often-overlooked entity. J. Appl. Physiol. 115:949.
Kotwal, J., C. V. Apte, A. Kotwal, B. Mukherjee, and J. Jayaram. 2007. High altitude: A hyper coagulable state: Results of a prospective cohort study. Thromb. Res. 120:391-397.

Kotwal, J., A. Kotwal, S. Bhalla, P. K. Singh, and V. Nair. 2015. Effectiveness of homocysteine lowering vitamins in prevention of thrombotic tendency at high altitude area: A randomized field trial. Thromb. Res. 136:758-762.

Krämer, A., J. Green, J. Pollard Jr., and S. Tugendreich. 2014. Causal analysis approaches in Ingenuity Pathway Analysis. Bioinformatics 30:523-530.

Kulkarni, Y. M., V. Suarez, and D. J. Klinke 2nd.. 2010. Inferring predominant pathways in cellular models of breast cancer using limited sample proteomic profiling. BMC Cancer 10:291.

Kuo, G., C. Y. Wu, and H. Y. Yang. 2019. MiR-17-92 cluster and immunity. J. Formos. Med. Assoc. 118:2-6.

Lakota, K., P. Zigon, K. Mrak-Poljsak, B. Rozman, Y. Shoenfeld, and S. Sodin-Semrl. 2011. Antibodies against acute phase proteins and their functions in the pathogenesis of disease: A collective profile of 25 different antibodies. Autoimmun. Rev. 10:779-789.

Li, M., S. Tian, L. Jin, G. Zhou, Y. Li, Y. Zhang, T. Wang, C. K. L. Yeung, L. Chen, J. Ma, J. Zhang, A. Jiang, J. Li, C. Zhou, J. Zhang, Y. Liu, X. Sun, H. Zhao, Z. Niu, P. Lou, L. Xian, X. Shen, S. Liu, S. Zhang, M. Zhang, L. Zhu, S. Shuai, L. Bai, G. Tang, H. Liu, Y. Jiang, M. Mai, J. Xiao, X. Wang, Q. Zhou, Z. Wang, P. Stothard, M. Xue, X. Gao, Z. Luo, Y. Gu, H. Zhu, X. Hu, Y. Zhao, G. Plastow, J. Wang, Z. Jiang, K. Li, N. Li, X. Li, and R. Li. 2013a. Genomic analyses identify distinct patterns of selection in domesticated pigs and Tibetan wild boars. Nat. Genet. 45:1431-1438

Li, M., X. Zhou, J. Mei, X. Geng, Y. Zhou, W. Zhang, and C. Xu. 2014. Study on the activity of the signaling pathways regulating hepatocytes from G0 phase into G1 phase during rat liver regeneration. Cell. Mol. Biol. Lett. 19:181-200.

Li, X., F. Tian, and F. Wang. 2013b. Rheumatoid arthritis-associated micro RNA-155 targets SOCS1 and upregulates TNF-alpha and IL-1beta in PBMCs. Int. J. Mol. Sci. 14:23910-23921.

Lin, X. Q., S. L. Liang, S. Y. Han, S. P. Zheng, Y. R. Ye, and Y. Lin. 2013. Quantitative iTRAQ LC-MS/MS proteomics reveals the cellular response to heterologous protein overexpression and the regulation of HAC1 in Pichia pastoris. J. Proteomics 91:58-72.

Lopez, J. P., A. Diallo, C. Cruceanu, L. M. Fiori, S. Laboissiere, I. Guillet, J. Fontaine, J. Ragoussis, V. Benes, G. Turecki, and C. Ernst. 2015. Biomarker discovery: quantification of microRNAs and other small non-coding RNAs using next generation sequencing. BMC Med. Genomics 8:35.

Lu, H., Y. Yang, E. M. Allister, N. Wijesekara, and M. B. Wheeler. 2008. The identification of potential factors associated with the development of type 2 diabetes: A quantitative proteomics approach. Mol. Cell. Proteomics 7:1434-1451.

Lu, Z. N., and Y. L. Feng. 2007. Nutritional Needs and Feed Components of Dairy Cows. Rev. 3rd ed. China Agricultural University Press, Beijing, China.

Ma, J. Y., L. Zhao, H. Y. Li, C. L. Li, and D. Z. Luosang. 2016. Major measures to improve the Jersey calves survival rate of high altitude localities. Chin. Cattl. Sci. 42:72-74.

Ma, L., J. Teruya-Feldstein, and R. A. Weinberg. 2007. Tumour invasion and metastasis initiated by microRNA-10b in breast cancer. Nature 449:682-688.

Markiewski, M. M., B. Nilsson, K. N. Ekdahl, T. E. Mollnes, and J. D. Lambris. 2007. Complement and coagulation: Strangers or partners in crime. Trends Immunol. 28:184-192

Ministry of Agriculture. 2004. Feeding Standard of Dairy Cattle (NY/T 34-2004). Ministry of Agriculture of China, Beijing. China.

Mishra, K. P., and L. Ganju. 2010. Influence of high altitude exposure on the immune system: A review. Immunol. Invest. 39:219-234.

Mishra, K. P., L. Ganju, and S. B. Singh. 2015. Hypoxia modulates innate immune factors: A review. Int. Immunopharmacol. 28:425428

Ou, M., X. Zhang, Y. Dai, J. Gao, M. Zhu, X. Yang, Y. Li, T. Yang, and M. Ding. 2014. Identification of potential microRNA-target 
pairs associated with osteopetrosis by deep sequencing, iTRAQ proteomics and bioinformatics. Eur. J. Hum. Genet. 22:625-632.

Poitz, D. M., A. Augstein, C. Gradehand, G. Ende, A. Schmeisser, and R. H. Strasser. 2013. Regulation of the Hif-system by micro-RNA 17 and $20 \mathrm{a}$-Role during monocyte-to-macrophage differentiation. Mol. Immunol. 56:442-451.

Ramírez-Tejero, J. A., E. Martínez-Lara, A. Rus, M. V. Camacho, M. L. Del Moral, and E. Siles. 2018. Insight into the biologica pathways underlying fibromyalgia by a proteomic approach. J. Proteomics 186:47-55.

Robinson, M. D., D. J. McCarthy, and G. K. Smyth. 2010. edgeR: A Bioconductor package for differential expression analysis of digital gene expression data. Bioinformatics 26:139-140.

Rodriguez, A., E. Vigorito, S. Clare, M. V. Warren, P. Couttet, D. R. Soond, S. van Dongen, R. J. Grocock, P. P. Das, E. A. Miska, D. Vetrie, K. Okkenhaug, A. J. Enright, G. Dougan, M. Turner, and A. Bradley. 2007. Requirement of bic/micro RNA-155 for normal immune function. Science 316:608-611.

Schoene, R. B. 2008. Illnesses at high altitude. Chest 134:402-416.

Selbach, M., B. Schwanhausser, N. Thierfelder, Z. Fang, R. Khanin, and N. Rajewsky. 2008. Widespread changes in protein synthesis induced by microRNAs. Nature 455:58-63.

Simpson, L. J., S. Patel, N. R. Bhakta, D. F. Choy, H. D. Brightbill, X. Ren, Y. Wang, H. H. Pua, D. Baumjohann, M. M. Montoya, M. Panduro, K. A. Remedios, X. Huang, J. V. Fahy, J. R. Arron, P. G. Woodruff, and K. Mark Ansel. 2014. A microRNA upregulated in asthma airway $\mathrm{T}$ cells promotes TH2 cytokine production. Nat. Immunol. 15:1162-1170.

Terasaka, N., A. Hiroshima, A. Ariga, S. Honzumi, T. Koieyama, T. Inaba, and T. Fujiwara. 2005. Liver X receptor agonists inhibit tissue factor expression in macrophages. FEBS J. 272:1546-1556.

Thai, T. H., D. P. Calado, S. Casola, K. M. Ansel, C. Xiao, Y. Xue, A. Murphy, D. Frendewey, D. Valenzuela, J. L. Kutok, M. SchmidtSupprian, N. Rajewsky, G. Yancopoulos, A. Rao, and K. Rajewsky. 2007. Regulation of the germinal center response by micro RNA-155. Science 316:604-608.

Thiersch, M., E. R. Swenson, T. Haider, and M. Gassmann. 2017. Reduced cancer mortality at high altitude: The role of glucose, lipids, iron and physical activity. Exp. Cell Res. 356:209-216.
Wang, M. Q., W. Ni, C. Tang, J. H. Guo, H. M. Zhang, M. X. Li, D. J. Ji, Z. P. Yang, and Y. J. Mao. 2018. Comparative analysis of milk production traits between Jersey and Holstein. Acta Ecologiae Animalis Domastici 7:37-41.

Wang, Y., J. Yu, W. Wang, J. Y. Zhang, Q. Yu, and Z. M. Wang. 2011. Studies on the characteristics and adaptive breeding of Jersey cattle. Chin. Dairy. Cattl. 11:47-48.

Yang, M., L. X. Lin, J. Wang, Z. L. Zhang, and E. W. Yuan. 2009. Changes of humoral immunity in new born infants with hypoxicischemic encephalopathy and its correlative factors. J. Appl. Clin. Pediatr. 2:119-121.

Yu, H., L. Cong, Z. Zhu, C. Wang, J. Zou, C. Tao, Z. Shi, and X. Lu. 2015. Identification of differentially expressed microRNA in the stems and leaves during sugar accumulation in sweet sorghum. Gene 571:221-230.

Yuan, Q. Y., and Z. Xie. 2005. Advances in animal adaptability to high altitude hypoxia. Prog. Physiol. Sci. 2:179-182.

Yusuf, N. H., W. D. Ong, R. M. Redwan, M. A. Latip, and S. V. Kumar. 2015. Discovery of precursor and mature microRNAs and their putative gene targets using high-throughput sequencing in pineapple (Ananas comosus var. comosus). Gene 571:71-80.

Zelcer, N., and P. Tontonoz. 2006. Liver X receptors as integrators of metabolic and inflammatory signaling. J. Clin. Invest. 116:607614.

Zhang, H., A. Y. Liu, P. Loriaux, B. Wollscheid, Y. Zhou, J. D. Watts, and R. Aebersold. 2007. Mass spectrometric detection of tissue proteins in plasma. Mol. Cell. Proteomics 6:64-71.

Zhang, M. J., H. S. Hao, H. B. Zhu, W. H. Du, and D. Wang. 2008. Jersey cattle - An important genetic resource for dairy production in China. Chin. Dairy Cattl. 1:11-14.

Zhang, S., Y. Y. Li, H. L. Cui, S. T. Chen, and J. Z. Wang. 2012. Effect of high altitude stress on serum $\mathrm{K}^{+}, \mathrm{Na}^{+}, \mathrm{Ca}^{2+}, \mathrm{Cl}^{-}, \mathrm{P}^{5+}$ in dairy cow. Chin. Cattl. Sci. 38:26-27.

Zhao, Y., and Y. H. Zhao. 2013. Effect of Astragalus membranaceus injection on immune function of neonates with hypoxic -ischemic brain damage. Zhongguo Fuyou Baojian 33:5475-5478. 